\title{
The Role of Symbiotic Approaches to Socio-Cultural Change in The Twenty-First Century: The Principles and Uses of The Symbiotic Approach to Socio-Cultural Change
}

\author{
Sujay Rao Mandavilli
}

\begin{abstract}
This paper emphasizes the importance and relevance of the proposed Symbiotic school of socio-cultural change in the context of the Twenty-first century. The approaches that we propose may also be referred to as 'Cultural Osmosis', and seek to replace older schools and theories of Cultural Change. This would lead to Cultural integration with different cultures still retaining some of their own unique characteristics. The ethics and the pros and cons of activism are also explored, along with their role in aiding cultural remediation. This paper also introduces concepts such as the theory of mindorientations, the theory of cultural orientations and the theory of Mind space as well. These approaches are expected to integrate with Applied Anthropology and Developmental Anthropology take them to greater heights. We conclude by discussing the potential real-world applications of Symbiotic Models of socio-cultural change.
\end{abstract}

\section{INTRODUCTION}

Various definitions of the term culture have been proposed by different Cultural Anthropologists such as Edward B.Tylor, Bronislaw Malinowski, Marwin Harris and others over the ages. Among these, the Edward B. Tylor's definition is generally considered to be the most comprehensive. He stated, "Culture or civilization taken in its broad ethnographic sense is that complex whole which includes knowledge, belief, art, morals, laws, customs, and any other capabilities and habits acquired by man as a member of society."

Various schools of cultural change have emerged ever since the field of Cultural Anthropology began to take shape some one hundred and fifty years ago. The oldest school of cultural change is the Uni-linear school of evolution which was propounded by Edward B. Tylor and Lewis Henry Morgan, among others. This school proposed that all societies passed through the stages of primitive savagery, barbarianism and culminated ultimately in complex civilizations. The Uni-linear school of evolution was replaced by the multi-linear school of evolution, and this school was founded by Leslie A. White, and Julian Steward. Another important school of thought is the Diffusionist school of thought which evolved in the late nineteenth and early twentieth Centuries. According to this school, cultural change began in a particular region, and spread to other regions. The school of Historical Particularism proposed by Franz Boas, rejected Uni-linear approaches to evolution, and proposed that cultural attributes were primarily due to that culture's unique historical factors. The Culture and Personality school founded by Ruth Benedict, Margaret Mead, Abram Kardiner and Ralph Linton attempted to study the relationship between human personality and cultural attributes. The idea of functionalism proposed by Bronislaw Malinowski, A R Radcliffe Brown and others in the 1930's, sought to identify the roles played by different elements of a culture in maintaining a cultural or a social system. The idea of Structuralism was propounded by Claude Levi-Strauss. 
According to him, elements of culture such as arts, ritual and the patterns of daily life were surface representations of the underlying structure of the human mind. 12345

In two previously published papers, we had proposed the 'Symbiotic approach to Sociocultural change' which we believed would be more relevant for the needs of the Twenty-first century characterized by the disappearance of borders and the spread of technology. In this paper, we present the salient features of this approach for international audiences, with the hope that this will be the springboard for the exchange of meaningful ideas and debates. 67

One of the key principles of this approach is that socio-cultural integration tends to increase over a period in time due to technological factors and better socio-economic integration. While there could be periods of reactionary or self-imposed autarchy in different parts of the world from time to time, these would pale into insignificance or eventually be left by the wayside. This would be akin to an 'Ascending wave', and make this approach all the more relevant. We had also proposed that a pro-active approach to socio-cultural change be adopted instead of studying cultures as merely objects of interest. This will ensure that undesirable elements of a culture are rooted out, and more desirable aspects be allowed to flourish. This is related to the principle of 'Social Darwinism'; however, desirable aspects of a culture do not always persist, as the relatively undesirable aspects of more dominant cultures tend to propagate and dominate in the long-term. Cultural traits also do not disseminate widely in a society due to factors such as lack of education and infrastructure. We had also proposed the philosophy of neo-centrism. This would involve an ideology-free and culture-neutral approach to an assessment of issues characterized by dialectical approaches. Another feature of this approach is its long-term orientation which means that long-term goals and considerations must take precedence and short-term goals and concerns, must be eventually merged with long-term goals and concerns.

The Anthropologist would play a crucial role in bringing about change by orchestrating government intervention or intervention through government parties. This must be done carefully and after taking a culture's sensitivities into account. This is by no means easy, and he may choose to do this though dialogue, discussions and deliberations. In order to do this, he would also need to break down a culture into its constituents or traits and attributes. This is typically known as a cultural taxonomy. Cultures are also associated with various enablers such as the strength of government institutions, the legal framework, the education system, language policy, the role of religion in society, social security, risk appetite and appetite for innovation. Etc and these would dictate the flexibility of a culture.

We had also categorized cultures into the following categories:

1. Dominant or influential cultural systems which would include counties such as the USA. Dominant cultural systems would be associated with technological superiority,

\footnotetext{
${ }^{1}$ A History of Anthropology, Thomas Hylland Eriksen and Finn Sivert Nielsen, Second Edition, Pluto Press

${ }^{2}$ A New History of Anthropology Edited by Henrika Kuklick, Blackwell publishing, 2008

3 Anthropology Carol R.Ember, Melwin Ember, Peter N. Peregrine, 12th Edition, Pearson Education Inc., 2008

${ }^{4}$ Cultural Anthropology Barbara Miller, 6th Edition, PHI Learning Private Limited, 2011

${ }^{5}$ Evolutionary Theories of Cultural Change: An Empirical Perspective, Richard R. Nelson Columbia University

${ }^{6}$ Articulating comprehensive frameworks on socio-cultural change: Perceptions of social and cultural change in contemporary Twenty-first century Anthropology from a 'Neo-centrist' perspective Published in ELK Asia Pacific Journal of Social Sciences Volume 3, Number 4 (July 2017 - September 2017) Sujay Rao Mandavilli

7 The relevance of Culture and Personality Studies, National Character Studies, Cultural Determinism and Cultural Diffusion in Twenty-first Century Anthropology: As assessment of their compatibility with Symbiotic models of Socio-cultural change ELK Asia Pacific Journal of Social Science Volume 4, Issue 2, 2018 Sujay Rao Mandavilli
} 
economic influence, cultural hegemony, military influence, soft power, military influence, population and population growth.

2. Non-Dominant cultural systems: Examples of such systems include China and India. Even though such cultures may have some potential, they lack dominance in the international arena due to an absence of hard power or soft power. This would ensure that their cultural traits do not spread.

3. Fringe or Marginal cultural systems: Examples of such systems include Tunisia and Zambia. Such countries are insignificant and cannot impact the world to any substantial degree.

4. Closed or Autarchic cultural systems: Examples of such cultures are North Korea which are isolated from the rest of the world. These cultures may also be assessed based on their Degree of Autarchy.

The process of symbiosis between these cultural systems would determine the global sociocultural landscape, and this is an ongoing process which will continue ad infinitum. This may be left to happen by itself, and this would constitute a laissez-free approach.

Several factors would determine a culture's ability to dominate. These include Technological superiority and Military hegemony, Cultural hegemony and soft power, Economic Influence, Population and population growth

Several factors would determine the ability of the culture to receive elements from other cultures. This would include Technological superiority, perceived superiority, Allure or glitz, the ability of the element to provide solutions to problems, comparison with substitutes, its economy and cost-effectiveness, utility and practicality etc. The culture must be receptive enough to accept the new element, and it must fill in a void as well. This would lead to a cultural homogenization of sorts, but this process cannot continue beyond a certain point as individual cultural differences will prevail.

Cultural boundaries which will be useful in studying the process of socio-cultural change, may be setup based on linguistic boundaries, ethnic boundaries, political boundaries, quasi-political boundaries such as provinces, cultural areas, areas where a religion is practised, cultural area demarcation based on types of artefacts, or types of economic systems followed. Cultural boundaries must also be drawn up based on parameters such as ease of data collection, ease of comprehension, manageability and utility in downstream studies.

The process of cultural symbiosis takes place in several stages such as a generation of awareness of other cultures, establishment of direct or indirect contact, or allowing diffusion without contacts. A change in popular sentiment may also be a pre-requisite for change. The new element is then seeded through a push approach (pushed from an external source), a pull approach (driven by demand), a push-pull approach or through sub-conscious adoption. This would be followed by the acceptance of the element in a modified or an unmodified form followed by a process of internalization.

Changes may be adopted by elites (Top-down approach), may take place horizontally without regard to socio-economic status or other criteria, or may be initiated from the bottom of the pyramid in a few cases, or may spread by function, starting from education sector etc.

If change is brought in proactively, it involves steps such as awareness of other cultures, steps to overcome social inertia, setting the ball rolling and collecting feedback as necessary. Areas of 
cultural lag based on socio-economic differentiation and geographical differentiation may also be identified for remediation.

\section{Mind-orientation, Mind space and Cultural remediation}

We had also proposed the theory of individual mind-orientation and mind space which could be one way of bringing about cultural remediation and cultural change. An individual may have a primary mind-orientation and several secondary mind-orientations. We see this as being vastly superior to the idea of personality which is not readily amenable to measurement of cultural change. ${ }^{8}$

There may be several types of mind-orientation, for example:

- Family orientation: In this case, the individual's efforts are primarily geared towards the satisfaction of familial needs.

- Societal Orientation: This type of Mind-orientation tends to put the well-being and needs of society above individual and all other needs.

- Employment or Business orientation: In this case, the individual's efforts are primarily geared towards employment of business. I.e. satisfaction of livelihood needs, and all other efforts are subservient to these.

- Individual mind-orientation: In this case, the individual sends to be self-centric in his pursuits. This type of orientation is characterized by a great emphasis or satisfaction of individual goals and aspirations.

- Religious, spiritual or philosophical orientation: In this case, a great deal of importance is placed on religious, spiritual or philosophical needs often at the expense of all other needs.

- Intellectual or creative orientation: In this type, a great deal of importance is placed on intellectual needs and creativity.

- Militant-orientation: In this type of orientation, individuals are geared to fight and protect society from external threats and forces. This type of mind-orientation may be more common in tribal and feudal societies.

- The Anarchist or the queer man: This type of mind-orientation may not be a bona fide category per se but a residual type and may be characterized by a partial or complete disorientation on some or many fronts.

- Other types of Basic mind-orientation: Other types of basic mind-orientation may also defined with a proper justification, but most may be subservient to, and slotted into the above categories.

The idea of mind-orientation is very useful because it can prove to be a cog in the wheel in the development of country-specific economic models, and can help in the development of pedagogical techniques as well. Suitable remediation strategies can be developed after a relationship between various mind-orientations and economic performance is clearly established. Individuals mould their mind-orientations in accordance to the orientations of society, and changing societal orientations, can in turn bring about a change in individual mind-orientations.

We discussed the concept of 'mind space' which stems from the fact that every individual has limited time at his disposal, or limited bandwidth to focus on multiple issues. Thus, more time spent watching television means less time for other pursuits. This impacts aspects of people's lives such as reading skills, linguistic ability etc, and has many downstream implications. Mind

${ }^{8}$ Strategies of Attitude changes, Robert Bandura, 1969 
space may be bounded or non-bounded. For example time, spent on cultural pursuits may not be swapped for scientific pursuits. The cultural Anthropologist must keep this in mind during the process of cultural remediation, and this may have several downstream impacts such as pedagogy. Unlike personality studies, this can be modelled in fairly non-abstract terms and may be of great use in Anthropological studies.

This approach also defines thought worlds which are the mental processes in an individual. These can be analysed through interviews, questionnaires, projective techniques such as Thematic apperception tests etc, so that a multi-dimensional analysis is possible. Changing thought worlds will in turn impact mind space and bring about changes in individual and mind-orientation.

\section{Cultural Remediation}

Cultural remediation may be carried out after studying Cultural orientations or the orientations of a society, and we propose the Seven Cultural Orientations as described below. These are modal orientations, and there will always be outliers in terms of disparate groups and individuals:

\section{Past-orientation versus future-orientation}

Past-orientation versus Future-orientation is the relative emphasis placed by a society or culture on its past and its future. Future-orientation is associated with characteristics such as planning, foresight, personality development directly and with other characteristics such as individualism indirectly, and an over-emphasis on the past tends to neglect these attributes.

Inward-looking cultures versus outward cultures

Some cultures are undoubtedly more outward-looking than others, and many have traditionally been so. This may also be referred to as the internal or external orientation of society. A change in a society's orientation will increase its cultural receptivity and lead to positive effects in society.

\section{Rigid versus flexible cultures}

Cultures can also be classified into rigid and flexible cultures. Flexible cultures are those with less cultural and intellectual baggage, and are more adaptable and flexible as a result.

\section{Individualistic versus collective cultures}

Some cultures like the USA may be more individualistic, while some others like the former communist countries emphasized collective thought and statism.

\section{Material and non-material orientation}

Some cultures like the USA may have placed more emphasis on materialism, while some other developed countries like Japan were much less materialistic. Other developing countries and least developed countries may be much less materialistic.

\section{Contentment versus innovation}

Some cultures do not wish to effect changes to the status quo, while some others pursue a relentless quest for perfection and changes in the status quo and this metric would indicate a culture's appetite for innovation

\section{Rational-orientation versus Non Rational-orientation}

In a rational society, less reliance is placed on myths, legends, superstitions etc, and rational societies tend to be much more progressive. 
The Anthropologist may wish to slot different cultures into these categories so that they can be benchmarked with other cultures and steps taken for cultural remediation.

\section{Applications of a Symbiotic study of Socio-cultural change}

The following are the potential benefits and applications of a Symbiotic study of Socio cultural change:

\section{Cultural analysis, predictive modelling and long-term cultural analysis}

One of the key benefits of a Symbiotic approach to socio-cultural change is that is presents new tools that can be of great utility in any socio cultural analysis. This approach combines features of approaches such as unilinear models of cultural evolution, multilinear models of cultural evolution, historical particularism and culture and personality studies taking into account the circumstances of the Twenty-first century along with other all-new tools and techniques that we have discussed that can be of use in cultural analysis, cultural modelling and predictive analysis linked to a variety of remediation techniques.

\section{As a guide to activists: where, when, what, how}

This paper emphasises activism as a tool to speed up the process of socio-cultural change. We have also discussed some methods available at an Anthropologists disposal to bring about socio-cultural change. This approach can serve as a heuristic tool and guide the Anthropologist on where to focus his efforts at what time and by how much. Thus, the Anthropologist may focus his attention on major influencing cultures, wayward cultures or areas of cultural lag for a maximum return on time and money. Cultures that can be more readily accessed and those that are flexible to change must also be targeted for intensive focus, as this approach will result in maximum return on investment.

\section{As a tool for theorization and ideation}

This approach can be used as a tool for theorization and the formulation of general laws that can be used for any study across cultures. For example, religious beliefs may not change easily in most cultures. Changes to food habits too may change slowly, but faster than religious beliefs. These may be called 'Universals of Cultural change',

\section{As a tool for corporate decision-making}

This approach can be used in corporate decision making along with other decision-making techniques. The Cultural Anthropologist can provide the organization with valuable advice on the implication of globalization for the company. The Anthropologist may also highlight social issues that are relevant to corporate decision-making. The Anthropologist can help ratify marketing plans and forecasts and can also help prepare culture-specific plans. He can also help advice on the likely demand for the company's products on the basis of social and other data. These can be used in addition to methods already in vogue.

\section{As a tool for economists to develop context-specific economic development models}

This approach can be used as a tool for economists to develop context-specific economic development models on the basis of a study of mind-orientation and thought worlds. Thus, culture-specific mores and norms can be used to interface various formalist and substantive models for greater welfare and economic growth, adding new meaning to Developmental Anthropology or Anthropology in Development. This will help avoid the dangers associated with one-size-fits-all approaches. Similarly, dimensional analysis can help identify outliers and laggards for quick remedial action. Thus, aid can be targeted towards individuals or groups that are more in need of it, not those that are more accessible or enjoy more clout. This approach can also help investigate why some cultures are more rigid than others and suggest potential remedial measures. Furthermore, economic development must be linked not only to 
a country's competitive advantage but to a society's cultural attributes. Thus, this approach can help lead to better economic welfare and faster economic growth. This is something only a Cultural Anthropologist is suitably equipped to do.

\section{As a tool for Government departments and planning agencies}

This approach can also serve as a tool to Government departments and planning agencies to help in economic planning activities by identifying outliers and laggards and performing a root cause analysis. The Cultural Anthropologist can also help formulate Culture-specific economic models and programs.

\section{As a guide for donor and international agencies}

This approach can also provide a guide to donor and international agencies to help them choose projects that provide the maximum return on investment with respect to a particular culture. This approach may help identify a list of people badly in need of developmental programmes. It can also provide a valuable guide to development conducive or changeunfriendly attitudes among different peoples in different communities. It can also identify if people of a particular community want change or not by providing a unique and a peoplecentric approach and perspective

\section{As a guide for Social workers}

There traditionally has been an interface between Cultural Anthropologists and social workers. Social workers need to understand not only social problems, but also cultural issues and the inferface of a given culture with society at large. Thus, Cultural Anthropologists can provide general and specific inputs to different types of Social workers such as Public Health workers. The tools and techniques proposed here can take their endeavours to a much higher level. ${ }^{9}$

\section{Better interface between Cultural Anthropology and psychology}

Psychologists have always investigated a range of topics such as personality development and behaviour. Social psychology, which is closely related to cultural anthropology, has also investigated man's behaviour in relation to his environment. Cultural Anthropologists have been interested in branches of psychology, but have largely kept personality structures constant to investigate variations in social structure. This exercise attempts to remediate the flaws of such an approach and provide a better integration between the two fields. ${ }^{10}$

\section{Research on the ethics of activism}

This approach can be used as a platform for further research on the ethics of activism from an emic and a stakeholder perspective instead of imposing his own points of view. Activism can take on many forms such as Action Anthropology which a technique that combines research and activism. This approach was first popularized by the American Anthropologist Sol Tax..

Other uses and potential applications will present themselves with the passage of time greatly enriching the role of a Cultural Anthropologist, and provide him with new value and meaning.

\footnotetext{
${ }^{9}$ Research Methods in the Social Sciences, David Nachimas and Chava Nachimas, St Martin's press, New York, 1976

10 Fundamentals of Social Psychology Robert A Baron et al Pearson 2012
} 